\title{
Prevalence and Associated Factors of Sleep Quality among Adults in Jimma Town, Southwest Ethiopia: A Community-Based Cross-Sectional Study
}

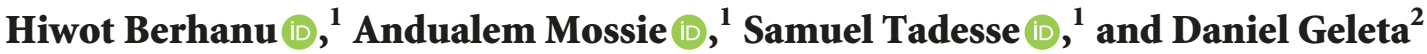 \\ ${ }^{1}$ Department of Medical Physiology, Jimma University, P.O. Box 378, Jimma, Ethiopia \\ ${ }^{2}$ Department of Child Health, John Snow International Research \& Training Institute, P.O. Box 138998, Addis Ababa, Ethiopia \\ Correspondence should be addressed to Hiwot Berhanu; hiwed2010@gmail.com
}

Received 2 November 2017; Revised 12 February 2018; Accepted 5 March 2018; Published 22 April 2018

Academic Editor: Yuan-Yang Lai

Copyright (c) 2018 Hiwot Berhanu et al. This is an open access article distributed under the Creative Commons Attribution License, which permits unrestricted use, distribution, and reproduction in any medium, provided the original work is properly cited.

\begin{abstract}
Background. An estimated 150 million people worldwide and nearly $17 \%$ of the populations in the developing nations are currently suffering from sleep problems. The aim of the present study was to determine the prevalence and associated factors of sleep quality among adults in Ethiopia. Method. A cross-sectional study was conducted on 422 randomly selected adults using validated and pretested Pittsburgh Sleep Quality Index. Data were entered into EpiData and analyzed using SPSS version 20 considering bivariable $(P$ value $<0.25)$ and multivariable $(P<0.05)$ logistic regression procedures at $95 \%$ confidence interval. Result. The overall prevalence of poor sleep quality (PSQI score $>5$ ) was $65.4 \%$ with higher proportion among males $(79(63.0 \%))$ and age group of 40-49 years $(174(28.6 \%))$. A multivariable logistic regression analysis indicated that age category of 40-49 years (AOR $=2[95 \% \mathrm{CI}(1.1,3.6)])(P=0.03)$, monthly income $\leq 1000 \mathrm{ETB}(\mathrm{AOR}=2.2[95 \% \mathrm{CI}(14,3.5)])(P=0.01)$, current khat chewing $(\mathrm{AOR}=1.8[95 \% \mathrm{CI}(1.1,3.1)])(P=0.03)$, daily khat chewing $(\mathrm{AOR}=3.4[95 \% \mathrm{CI}(1.2,11.1)])(P=0.04)$, and obesity $(\mathrm{AOR}=$ $1.2[95 \%$ CI $(1.3,2.5)])(P=0.03)$ were identified as risk factors of poor sleep quality. Conclusion. The current study is informative for government to work on poverty reduction, create awareness for weight reduction, and develop legislation for khat control to prevent poor sleep quality.
\end{abstract}

\section{Introduction}

Sleep is part of what is called the sleep-wake cycle. This cycle, which consists of roughly 8 hours of nocturnal sleep and 16 hours of daytime wakefulness in humans, is controlled by a combination of two internal influences: sleep homeostasis and circadian rhythms [1]. In contrast to wakefulness, sleep is a period of inactivity and restoration of mental and physical function. It has been suggested that sleep provides time for entering information that has been acquired during periods of wakefulness into memory and for reestablishing communication between various parts of the brain. Sleep also is a time when other body systems restore their energy and repair their tissues [2] and is fundamental to wellbeing and optimal health [3-5]. People who get enough quality sleep have more energy, better cognitive function, healthier immune systems, and improved memory, alertness, attentiveness, and performance throughout the day [6]. Many hormones, such as growth hormone, are produced in a cyclic manner correlating with the sleep-wake cycle, suggesting that growth and tissue repair may occur during sleep. Another hormone produced towards the end of the night is the stress hormone cortisol, which begins to increase in preparation for the anticipated stress of the day, usually capped by a particularly large increase (up to 50\%) about 20-30 minutes after waking, known as the cortisol awakening response [7]. Although sleep is one of the basic needs of human beings and is important to their health $[8,9]$, its problem has a wide range of causes including medical and psychological conditions. Some sleep problems are caused by restriction of the upper airway, while others are caused by genetic conditions. Other factors that affect sleep are age, medications, diet, and environmental factors, such as shift work. Sleep problem covers a broad spectrum of symptoms and is mostly characterized by one 
or more of symptoms like fatigue, inability to fall asleep at night, inability to stay asleep at night, excessive daytime sleepiness, loud snoring or gasping sounds during sleep, sleep attacks or unintended episodes of falling asleep, loss of muscle control or inability to move, and unusual behaviors such as sleep walking [10]. While sleep problems have existed for centuries, it is only within the last 3 to 4 decades that attention has focused on their diagnosis and classification [11]. To understand and assess sleep at different level, different methods have been developed to assess duration, distribution during the 24-hour day period, and quality of sleep [12]. Most often, the diagnosis of sleep problem usually is based on an adequate sleep history, physical examination, and a sleep diary or sleep log, where in some cases sleep laboratory studies may be needed to arrive at an accurate diagnosis [13]. Currently, the Pittsburgh Sleep Quality Index (PSQI) is an effective instrument used to measure the quality and patterns of sleep in adults by differentiating poor sleepers from good sleepers [14]. Sleep quality changes as a function of normal aging, in terms both of decreased duration and consolidation. Recent findings suggest that sleep quality plays a critical role in preserving cognitive function in older adults, reducing the risk of dementia [15], and it is identified to have bidirectional relationship with physical activity [4]. The National Sleep Foundation and consensus statement of the American Academy of Sleep Medicine and Sleep Research Society suggest that adults should sleep 7 or more hours per night on a regular basis to promote optimal health $[5,16,17]$. Not getting enough sleep can affect quality of life and untreated sleep problems can cause serious health problems and medical issues [18]. Researchers at the UK's University of Warwick Medical School conducted large-scale, multinational study of sleep disorders among eight countries in Asia and Africa which showed an overall rate of nearly $17 \%$ of the populations in these developing nations suffering from sleep problem. This is a figure not too far from the average $20 \%$ of the populations of the developed world that are believed to struggle with sleep problems of one form or another [19]. The levels of sleep difficulties experienced in developed nations like USA estimated that 50 to 70 million people are chronically suffering from sleep disorders [20]. The prevalence of sleep problems in mostly rural areas of developing nations is underestimated; researchers found a great deal of variation in the frequency of sleep difficulties. Some areas experienced very low levels of sleep disorders and others have conspicuous sleep problem. In South Africa, $31.3 \%$ of women and $27.2 \%$ of men reported difficulty with sleep. Overall rates of sleep problem in the remaining African nations of Tanzania, Ghana, and Kenya ranged between 8.3\% and $12.7 \%$ and it is more prevalent than heart disease, cancer, AIDS, neurologic disease, breathing problems, diabetes, and gastrointestinal problems [19]. The prevalence of poor sleep quality (PSQI > 5) in general population as reported by study conducted among substance abusers in Cleveland, Ohio, was noted in $15 \%$ of the subjects [21]. Similarly, in China's population, the prevalence of poor sleep quality was reported to be $41.5 \%$ with a higher rate to be observed in elderly females (45.8\%) than in elderly males (35.8\%). The prevalence rate increased with age, from $32.1 \%$ (aged 60-69 years) to
$52.5 \%$ (aged $\geq 80$ years). The study also showed that less duration of education poses about 1.04 times risk and living alone was reported to cause 1.62 times poor sleep quality than their counterparts [22]. Another study conducted in China reported being female (45.8\%) to be greater risk factor for poor sleep quality than being male $(35.8 \%)$ [23, 24], whereas a study conducted in Lahore University showed the existence of similar level of poor sleep quality in both sexes [25]. A study done in Brazil indicates that individuals with higher socioeconomic status and education levels sleep better than those with lower socioeconomic status [23]. In Spain, the prevalence of poor sleep quality stands at $38.2 \%$, where women were almost twice as likely as men to have poor quality, further indicating age to have direct association with a low quality of sleep [24]. Similarly, a cross-sectional study's result in Brazil revealed a positive correlation between percentage of slow-wave sleep and percentage of lean body mass in women. In men, awakenings during sleep were correlated positively with indices such as body mass index, waist circumference, hip circumference, and waist-to-hip ratio [23] and women were noted to sleep more than men [26]. Meanwhile, in other studies, women and younger age reported lesser sleep disturbance [27]. In a cross-sectional study done in China among 1023 nurses, the prevalence of poor sleep was $56.7 \%$. Of these, 315 nurses (34.13\%) were rotating-shift workers; multivariate logistic regression revealed that rotating shifts were independent risk factor for poor sleep quality $[28,29]$. The prevalence of poor sleep quality was also reported in $54.7 \%$ of residents and $52.7 \%$ (51.8\% among males and $56.9 \%$ among females) of college students who participated in a cross-sectional survey conducted to assess sleep quality in Thailand and Ethiopia, respectively $[9,30]$. The previously conducted cross-sectional studies have identified that there is association between sex, residence, and substance use [31] (such as alcohol [32], khat [33-37], smoking $[38,39]$, caffeinated beverages $[35,40]$, and other stimulants) in different countries with poor sleep quality. Similarly, body composition [41], hypertension and Body mass index [42, 43], and diabetes mellitus [44] were reported by different studies of multiple countries to have association with poor sleep quality. Given the lack of merged studies on sleep quality in the previous review, in the current study, we performed assessment of sleep quality and associated factors. In addition, there are some limitations of previous studies to be highlighted. First, most of sleep studies were performed in Western countries, and few have been conducted in developing countries. So, due to differences in lifestyle and culture, findings obtained in Western countries might not be applicable to African populations in general and Ethiopia in particular. Second, while sleep quality contains quantity and quality parameters, the research on sleep is mostly focusing only on the quantity of sleep (sleep duration). Hence, this study is important to determine the problems and associated factors of sleep quality among adults population in the study area. Therefore, the aim of the present study was to determine the prevalence and associated factors of sleep quality among adults. 


\section{Methods}

2.1. Study Area and Period. The study was conducted in Jimma town, which is one of the towns in Oromia national regional state, from 1 April to 28 April in 2016. Jimma is located $357 \mathrm{Km}$ southwest of Addis Ababa. It is divided into 17 kebeles with a population of 120,960 and 32,192 households. A community-based cross-sectional study design was employed on randomly selected households. Sample size $(n)$ was determined using single population proportion formula using $14.7 \%$ prevalence of poor sleep quality among households based on previous study at $95 \%$ confidence interval and $5 \%$ margin of error. Considering $2 \%$ to overcome design effect and $10 \%$ nonresponse rate, we have premeditated to register 422 participants for final sample size [19].

Simple random sampling using lottery method was used to select six study kebeles. After the study kebeles were identified, proportional sample was allocated to the selected kebeles using population proportional to size using lists of all households (from the existing lists of households from registration book of health extension workers) as a sampling frame. Hereby, the study participants were selected by systematic random sampling technique using computergenerated method from the sampling frame. Data were collected by 6 data collection trained nurses employed from the study area. Data collectors briefed objectives and purpose of the study to household heads and requested informed consent to collect data. After consent was obtained, faceto-face interview was conducted using a structured and pretested questionnaire for sociodemographic and other data. To evaluate sleep quality, participants were asked using Pittsburgh Sleep Quality Index (PSQI). PSQI differentiates "poor" from "good" sleep quality by measuring seven areas (components): subjective sleep quality, sleep latency, sleep duration, habitual sleep efficiency, sleep disturbances, use of sleeping medications, and daytime dysfunction over the last month [14]. The composite scores obtained indicate "good" (score < 5) and "poor" (score > 5) sleepers. A score of 0 to 3 is assigned to each of the seven scales ( 0 meaning no problem). The sum of the global PSQI scores ranged from 0 to 21. Finally, the subject whose global PSQI score was 5 or less was considered to have good sleep quality [9]. Finally, the data collectors measured weight (to the nearest $0.1 \mathrm{gm}$ ), height, hip and waist circumferences (to the nearest 0.1 centimeter), and $\mathrm{BP}$ (to the nearest $0.5 \mathrm{mmHg}$ ) of interviewed participants whose data were kept anonymous. Data were edited, coded, and entered into EpiData version 3.1 and exported to and analyzed by SPSS version 20. During the process of management, frequencies and percentages were calculated to describe the data by tables or figures. Bivariate analysis was performed separately using binary logistic regression to rank the relative importance of exposure variables with outcome variable using unadjusted odds ratios. The variables that have statistically significant (a $P$ value of $<$ 0.25 ) associations with the outcome variable in the bivariate analysis were further considered a candidate for stepwise multiple logistic regression model to control the effect of confounding variables. Finally, the variables that have statistically significant (a $P$ value of $<0.05$ ) associations with the sleep quality were considered as potential risk factors of sleep quality. The questionnaire was initially prepared in English, translated to local languages Afaan Oromo and Amharic, and retranslated to English by another person who was blind to the original questionnaire for consistency check. Pretesting of the questionnaire was made on $5 \%$ of sample size at one kebele (which was out of the main study kebeles) and corrective actions were taken accordingly by principal investigator. Once the quality of questionnaire was confirmed, two-day training was given for 6 data collectors and 1 supervisor by principal investigator focusing on the objective of the study and interview and measurement techniques. Completeness, accuracy, clarity, and consistency of every filled questionnaire were checked by the supervisor on daily basis. Checking for completeness and consistency of variables during data entry and analysis was continued before actual data analysis. Ethical clearance was obtained from Ethical Review Committee of Jimma University. The participants were informed and verbal consent was taken through signature or finger print.

\section{Results}

3.1. Sociodemographic Characteristics of Respondents. A total of 422 respondents were enrolled in the study, making $100 \%$ response rate. Of those enrolled, 257 (60.9\%) were males, while $165(39.1 \%)$ of them were females. The mean age of participants was 38.7 years $(S D \pm 12.5)$. More than half $(69.4 \%)$ of participants were married. Majority of the study subjects were Oromo in ethnicity $(68.5 \%)$ followed by Amhara (15.4\%).

Among religion groups, 223 (52.8\%) were Muslim, 28.2\% Orthodox, and $16.1 \%$ other religions followers. Concerning educational status, 106 (25.1\%) of respondents did not attend formal education, whereas $174(41.2 \%)$ and $142(33.6 \%)$ of them attended primary and secondary and above education, respectively. The of respondents (35.5\%) were merchants. The average monthly income of the recruited households was 1786.10 ETB (with SD \pm 1290.00 ) (Table 1).

3.2. Prevalence of Sleep Quality. The participants went to bed on average at 10:20 pm and rose in the morning at 5:50 am. Their average night sleep duration was 6.8 hours $(\mathrm{SD} \pm$ 2.1). Seven components of sleep quality in the present study were assessed and identified their sleep status. The average sleep latency of the participants was 25 minutes ( $S D \pm 15.0)$, and only $81(19.2 \%)$ of the participants reported that their subjective sleep quality was very bad. In the present study, 329 (78.0\%) of them reported that they had less than 7 hours of sleep per night, 217 (51.4\%) had a low habitual sleep efficiency $(<65 \%)$, and $100(23.7 \%)$ used sleep medication within the past one month at the time of interview (Table 2). The mean scores of subjective sleep quality, sleep disturbances, and daytime dysfunction were $1.5(\mathrm{SD} \pm 1.1), 1.4(\mathrm{SD} \pm 0.9)$, and 0.9 (SD \pm 0.8 ) hours, respectively. 276 (65.4\%) participants were assessed as poor sleepers by global PSQI score greater than 5. The prevalence of poor sleepers was higher among males $(174(63.0 \%))$ and the age group of $40-49$ years (79 $(28.6 \%))$. 
TABLE 1: Sociodemographic characteristics of the sampled $(n=422)$ adults in Jimma town, southwest Ethiopia, 2016.

\begin{tabular}{|c|c|c|}
\hline Variables & Number & $\%$ \\
\hline \multicolumn{3}{|l|}{ Age } \\
\hline $19-29$ years & 120 & 28.4 \\
\hline $30-39$ years & 114 & 27.0 \\
\hline $40-49$ years & 112 & 26.5 \\
\hline 50 years or above & 76 & 18.0 \\
\hline \multicolumn{3}{|l|}{ Sex } \\
\hline Male & 257 & 60.9 \\
\hline Female & 165 & 39.1 \\
\hline \multicolumn{3}{|l|}{ Religion } \\
\hline Muslim & 223 & 52.8 \\
\hline Orthodox & 119 & 28.2 \\
\hline Others* & 80 & 19.0 \\
\hline \multicolumn{3}{|l|}{ Ethnic group } \\
\hline Oromo & 289 & 68.5 \\
\hline Amhara & 68 & 16.1 \\
\hline Others ${ }^{* *}$ & 65 & 15.4 \\
\hline \multicolumn{3}{|l|}{ Educational status } \\
\hline No formal education & 106 & 25.1 \\
\hline Primary education & 174 & 41.2 \\
\hline Secondary and above & 142 & 33.6 \\
\hline \multicolumn{3}{|l|}{ Marital status } \\
\hline Married & 293 & 69.4 \\
\hline Unmarried & 69 & 16.4 \\
\hline Others ${ }^{* * *}$ & 60 & 14.2 \\
\hline \multicolumn{3}{|l|}{ Occupation } \\
\hline Government employee & 92 & 21.8 \\
\hline Housewife & 127 & 30.1 \\
\hline Merchant & 150 & 35.5 \\
\hline Others $^{* * * *}$ & 53 & 12.6 \\
\hline \multicolumn{3}{|l|}{ Monthly income } \\
\hline$>1000 \mathrm{ETB}$ & 224 & 53.1 \\
\hline$\leq 1000 \mathrm{ETB}$ & 198 & 46.9 \\
\hline
\end{tabular}

${ }^{*}$ Protestant, Catholic, Wakefata, and Jehovah. ${ }^{* *}$ Gurage, Tigre, Wolayta, Yem, and Dawro. ${ }^{* * *}$ Divorced and widowed. ${ }^{* * * *}$ Daily laborer, private employee, and home maid.

\subsection{Factors Associated with Sleep Quality}

3.3.1. Sociodemographic Factors Associated with Sleep Quality. In the bivariable logistic regression analysis, variables such as age, sex, education, occupation, and household monthly income were associated with sleep quality $(P<0.25)$ as presented in Table 3; particularly, age categories of 40-49 $[\mathrm{COR}=1.6,95 \% \mathrm{CI}(0.9,2.8), P=0.09]$ and $\geq 50$ years $[\mathrm{COR}$ $=1.4$, $\mathrm{CI}(0.9,2.6), P=0.23]$, being female $[\mathrm{COR}=0.8,95 \%$ $\mathrm{CI}(0.5,1.2), P=0.22]$, attaining primary education [COR $=$ $1.4,95 \% \mathrm{CI}(0.9,2.2), P=0.14]$, being a merchant $[\mathrm{COR}=$ $1.1,95 \% \mathrm{CI}(0.3,1.2), P=0.17]$, being a housewife [COR $=1.1$, $95 \%$ CI $(0.3,1.3), P=0.22]$, and household monthly income less than $1000 \mathrm{ETB}[\mathrm{COR}=2.2,95 \% \mathrm{CI}(1.5,3.4), P=0.22]$ were associated with poor sleep quality (Table 3 ).

\subsection{Substances Use and Its Association with Sleep Quality}

3.4.1. Khat Chewing Practices. As per the current study result, $287(68 \%)$ respondents chewed khat at least once in their life time. The overall past one month prevalence of khat chewing (current chewers) preceding the study was $51.2 \%$. Of these, $100(46.3 \%)$ chewers practiced khat chewing daily, whereas the remaining 57 (26.4\%) practiced it 1-3 times per week and $59(27.3 \%)$ practiced it 3-6 times per week. The amount of khat consumed at a time was estimated per cost in birr and 57 (26.4\%) of the chewers consumed khat that costs $>25$ birr per ceremony (Table 4). The current study indicated that current khat chewers $(54.0 \%)$ suffered from poor sleep quality [COR $=1.4,95 \% \mathrm{CI}(0.9,2.3), P=0.19]$. Moreover, individuals who used to chew khat daily $(46.6 \%)$ [COR $=1.7,95 \% \mathrm{CI}(0.8,3.3)$, $P=0.16]$ and cost above 25 ETB $(30.2 \%)[C O R=1.9,95 \%$ CI $(0.9,3.9), P=0.08$ ] for khat have demonstrated higher proportion of poor sleep quality as indicated in Table 4 .

3.4.2. Alcohol Consumption. Higher proportions of current alcohol consumers (drink alcohol in the past 30 days preceding the study) (54\%) were found to be poor sleepers, whereas association was observed in former consumers (12.8\%) [COR $=0.6,95 \% \mathrm{CI}(0.3,1.2), P=0.12]$ and current consumers (38.4\%) $[\mathrm{COR}=1.1,95 \% \mathrm{CI}(0.7,1.6), P=0.08]$. Beer was a kind of alcohol consumed by higher proportion (63.3\%) of poor sleepers, whereas association was demonstrated by other kinds of alcohol $(32.7 \%)[\mathrm{COR}=1.8,95 \% \mathrm{CI}(0.9,2.7)$, $P=0.12]$ as shown in Table 4 .

3.4.3. Body Composition. Height, weight, and waist circumferences were taken and body mass index was calculated for every participant from these measurements. Higher proportion of poor sleep was identified among overweight (30.4\%) groups. With regard to waist circumference, $70 \%$ of females and $40 \%$ of males were identified to be poor sleepers. Association between BMI and poor sleep quality was observed in obese group [7.6\%, COR $=0.6,95 \% \mathrm{CI}(0.3,13)$, $P=0.02]$ and waist circumference was observed in male sex $[40 \%, \mathrm{COR}=3.0,95 \% \mathrm{CI}(1.3,3.7), P=0.08]$ as indicated in Table 5.

3.4.4. Blood Pressure. Blood pressure of the subjects in a sitting position was taken from the left arm at their homes. For those with elevated BP, appointment was given on the next day and the second reading was taken. In this study, $20.7 \%$ of the study subjects with systolic hypertension (SBP $\geq 140 \mathrm{mmHg}$ ) and $13.8 \%$ with diastolic hypertension (DBP $\geq$ $90 \mathrm{mmHg}$ ) were identified to be poor sleepers. The result also showed association in both systolic $[20.7 \%, \mathrm{COR}=1.3,95 \%$ CI $(0.8,2.4), P=0.22]$ and diastolic hypertension $[13.8 \%$, COR $=1.6$, CI $(0.8,3.2), P=0.12]$ (Table 5).

3.4.5. Factors Independently Associated with Sleep Quality. All variables that had $P$ value $<0.25$ in the bivariate analysis were included in the multivariate analysis for backward logistic regression. From total variables included in the logistic regression model, four variables were found to be statistically significant at the level of $P<0.05$. Accordingly, 
TABLE 2: Sleep quality and its components scores among adults in Jimma town, April 2016.

\begin{tabular}{|c|c|c|c|}
\hline Variables $(n=422)$ & Value & Number & $\%$ \\
\hline \multirow{4}{*}{ Sleep duration } & $>7$ hours & 93 & 22.0 \\
\hline & 6-7 hours & 72 & 17.1 \\
\hline & 5-6 hours & 57 & 13.5 \\
\hline & $<5$ hours & 200 & 47.4 \\
\hline \multirow{4}{*}{ Sleep latency } & 0 & 65 & 15.4 \\
\hline & 1 & 157 & 37.2 \\
\hline & 2 & 112 & 26.5 \\
\hline & 3 & 88 & 20.9 \\
\hline \multirow{4}{*}{ Daytime dysfunction } & 0 & 191 & 45.3 \\
\hline & 1 & 138 & 32.7 \\
\hline & 2 & 85 & 20.1 \\
\hline & 3 & 8 & 1.9 \\
\hline \multirow{4}{*}{ Sleep efficiency } & $>85 \%$ & 78 & 18.5 \\
\hline & $75-84 \%$ & 159 & 37.7 \\
\hline & $65-75 \%$ & 140 & 33.2 \\
\hline & $<65 \%$ & 45 & 10.7 \\
\hline \multirow{4}{*}{ Subjective sleep quality } & Very good & 93 & 22.0 \\
\hline & Fairly good & 128 & 30.3 \\
\hline & Fairly bad & 120 & 28.4 \\
\hline & very bad & 81 & 19.2 \\
\hline \multirow{4}{*}{ Sleep disturbance } & 0 & 78 & 18.5 \\
\hline & 1 & 159 & 37.7 \\
\hline & 2 & 140 & 33.2 \\
\hline & 3 & 45 & 10.7 \\
\hline \multirow{4}{*}{ Use of sleep medication } & Not during the past month & 375 & 88.9 \\
\hline & Less than once a week & 30 & 7.1 \\
\hline & Once or twice a week & 8 & 1.9 \\
\hline & Three or more times a week & 9 & 2.1 \\
\hline \multirow{2}{*}{ Sleep quality score } & Good sleep & 146 & 34.6 \\
\hline & Poor sleep & 276 & 65.4 \\
\hline
\end{tabular}

age, monthly income, BMI, and khat chewing status of study subject were demonstrated to have statistically significant association with sleep quality. Moreover, participants in the age category of 40-49 years were 2 times [AOR $=2,95 \% \mathrm{CI}$ $(1.1,3.6), P=0.03]$ more likely to experience poor sleep quality than a person whose age was between 19 and 29 years. It was also identified that households with monthly income $\leq 1000$ ETB were two times more likely to experience poor sleep quality than households with monthly income above 1000 ETB. Similarly, current khat chewers were about twice $[\mathrm{AOR}=1.8,95 \% \mathrm{CI}(1.1,3.1), P=0.03]$ more likely to experience poor sleep quality than those who never chewed khat. Of the current khat chewers, subjects who chew daily were 3.4 times more likely to experience poor sleep quality $[\mathrm{AOR}=3.4,95 \% \mathrm{CI}(1.2,11.1), P=0.04]$ than a person who used to chew khat $1-3$ times per week. Finally, an obese person $\left(\mathrm{BMI}>30 \mathrm{~kg} / \mathrm{cm}^{2}\right)$ is 1.5 times $[\mathrm{AOR}=$ $1.2,95 \%$ CI $(0.3,2.5), P=0.03$ ] more likely to incur poor sleep quality than a person with normal range body mass index $\left(\mathrm{BMI}=18.5-24.9 \mathrm{~kg} / \mathrm{cm}^{2}\right)$ as shown in Table 6 . Some variables that demonstrated association in bivariable analysis like sex, educational status, occupation, alcohol consumption and kind of alcohol consumed, amount of coffee consumed per day, hypertension, and waist circumference have not demonstrated statistically significant association with sleep quality in final model. Therefore, they were not considered as potential independent factors of poor sleep quality.

\section{Discussions}

The current community-based study (used the validated PSQI) is the first to evaluate sleep quality and its associated factors among Jimma town's adult population. As a result, PSQI global score recognized $64.5 \%$ of participants to suffer poor sleep quality in preceding one month before the study. The proportion showed nearly similar prevalence and consistent result with the results of other studies in the literature [28]. However, the studies in Cleveland [21], china [22], Spain [24], Thailand [9], and Ethiopia (out of the current site) [30] reported lower proportion of sleep quality. Similarly, the overall rate of sleep quality in developing nations [19] including African nations (Tanzania, Ghana, and 
TABLE 3: Association between sociodemographic factors and poor sleep quality among sampled adults of Jimma town, April 2016.

\begin{tabular}{|c|c|c|c|c|c|}
\hline \multirow{2}{*}{ Variables } & \multicolumn{3}{|c|}{ Global PSQI score } & \multirow{2}{*}{$P$ value } & \multirow{2}{*}{$\operatorname{COR}(95 \% \mathrm{CI})$} \\
\hline & Poor sleepers $(n=276)$ & Good sleepers $(n=146)$ & $\operatorname{Total}(N)=422$ & & \\
\hline \multicolumn{6}{|l|}{ Age category } \\
\hline $19-29$ years & $72(26.1)$ & $48(32.9)$ & $120(28.4)$ & & 1.0 \\
\hline $30-39$ years & $73(26.4)$ & $41(28.1)$ & $114(27.0)$ & 0.53 & $1.2(0.7,2.1)$ \\
\hline $40-49$ years & $79(28.6)$ & $33(22.6)$ & $112(26.5)$ & $0.09^{*}$ & $1.6(0.9,2.8)$ \\
\hline$\geq 50$ years & $52(18.8)$ & $24(16.4)$ & $76(18.0)$ & $0.23^{*}$ & $1.4(0.9,2.6)$ \\
\hline \multicolumn{6}{|l|}{ Sex } \\
\hline Male & $174(63.0)$ & $83(56.8)$ & $257(60.9)$ & & 1.0 \\
\hline Female & $102(37.0)$ & $63(43.2)$ & $165(39.1)$ & $0.22^{*}$ & $0.8(0.5,1.2)$ \\
\hline \multicolumn{6}{|l|}{ Education } \\
\hline No formal & $71(25.7)$ & $35(24.0)$ & $106(25.1)$ & 0.30 & $1.2(0.8,2.2)$ \\
\hline Primary & $119(43.1)$ & $55(37.7)$ & $174(41.2)$ & $0.14^{*}$ & $1.4(0.9,2.2)$ \\
\hline$\geq$ Secondary & $86(31.2)$ & $56(38.4)$ & $142(33.6)$ & & 1.0 \\
\hline \multicolumn{6}{|l|}{ Occupation } \\
\hline Government employee & $68(24.6)$ & $24(16.4)$ & $92(21.8)$ & & 1.0 \\
\hline Housewife & $86(31.2)$ & $41(28.1)$ & $127(30.1)$ & $0.22^{*}$ & $0.6(0.3,1.3)$ \\
\hline Merchant & $88(31.9)$ & $62(42.5)$ & $150(35.5)$ & $0.17^{*}$ & $0.5(0.3,1.2)$ \\
\hline Others* & $34(12.3)$ & $19(13)$ & $53(12.6)$ & 0.32 & $0.7(0.4,1.5)$ \\
\hline \multicolumn{6}{|l|}{ Monthly income } \\
\hline$>1000 \mathrm{ETB}$ & $128(46.4)$ & $96(65.8)$ & $224(53.1)$ & & 1.0 \\
\hline$\leq 1000 \mathrm{ETB}$ & $148(53.6)$ & $50(34.2)$ & $198(46.9)$ & $0.00^{*}$ & $2.2(1.5,3.4)$ \\
\hline
\end{tabular}

Kenya [20] in particular) reported lower proportion of the problem. To the level of our review, there was no study report higher than the current prevalence report. The reported variations between different studies may be influenced by different socioeconomic demands and cultural habits among the different population groups. Literature indicates that rural residents are more likely to report good levels of sleep quality when compared to urban residents [45] due to different factors such as sleep habits, sleep hygiene, cultural and racial differences, lifestyle, life quality, and stresses. The higher percentage of sleep problem in the current study could be explained to be the result of differences in the aforementioned factors and study setting (the current study included participants only from urban setting unlike studies conducted in America and China which included participants from both urban and rural settings).

The substantial higher proportion of the prevalence was observed among males (63.0\%) unlike the study report conducted in South Africa [19] and China [22]. This might be due to the nature of the study participants in the area; males bear more responsibility to lead the family and substance users. In this study, sleep quality was significantly associated with age, monthly income, khat chewing, and body mass index in multivariable logistic regression analysis. This study identified that sleep quality is not continuously increasing with age as it was reported by the study conducted in China [22]. But age group of 40-49 years was identified to have higher risk for poor sleep quality than younger ages. This could be due to reduced melatonin levels as age increases compared with younger ages. Even though the clear mechanism is unknown, a variety of physiological and degenerative changes might cause degeneration of pathways from retina to pineal gland, and/or reduction of pinealocyte $\beta$-adrenergic receptor functions may contribute to lowering plasma melatonin levels and this may lead to poor sleep quality [37]. The other possible reason might be the testosterone decline at a rate of $1 \%$ per year leading to men being hypogonadal. In line with this fact, studies also indicated that lower levels of testosterone are connected to worse sleep consolidation in the form of reduced performance and increased frequency of awakenings [46]. Similarly, the possible reason might be the premenopausal/menopausal hormonal effects of estrogen in women. The possible mechanism could be that estrogen has been shown to decrease sleep latency, decrease the number of awakenings after sleep occurs, increase total sleep time, and decrease the number of cyclic spontaneous arousals. During the luteal (low estrogen) phase in premenopausal women, a twofold increase in the number of arousals occurs, particularly when both estrogen and progesterone levels are low [29].

Monthly income was another sociodemographic factor that showed relation with sleep quality. Individuals who earn $\leq 1000$ ETB were twice poor sleeper than those with higher monthly income. A study conducted in Britain reported that people with higher socioeconomic status have a better quality of sleep than that of the poor [23]. This possibly occurs from mental satisfaction that could be related to higher quality of physical living environment including bedding and clothing which could affect thermoregulation. Current khat chewers have demonstrated association (1.8 times higher risk) with 
TABLE 4: Substances use and its association with sleep quality among adults in Jimma town, southwest Ethiopia, April 2016.

\begin{tabular}{|c|c|c|c|c|c|c|c|c|}
\hline \multirow{3}{*}{ Variables } & \multicolumn{6}{|c|}{ Global PSQI score } & \multirow{3}{*}{$P$ value } & \multirow{3}{*}{ COR $(95 \% \mathrm{CI})$} \\
\hline & \multicolumn{2}{|c|}{$\begin{array}{l}\text { Poor sleepers } \\
\quad(n=276)\end{array}$} & \multicolumn{2}{|c|}{$\begin{array}{l}\text { Good sleepers } \\
\quad(n=146)\end{array}$} & \multicolumn{2}{|c|}{ Total $(N) 422$} & & \\
\hline & $n$ & $\%$ & $n$ & $\%$ & $n$ & $\%$ & & \\
\hline \multicolumn{9}{|c|}{ Khat chewing status } \\
\hline Never & 84 & 30.4 & 51 & 34.9 & 135 & 32.0 & & 1.0 \\
\hline Former & 43 & 15.6 & 28 & 19.2 & 71 & 16.8 & 0.81 & $0.9(0.5,1.7)$ \\
\hline Current & 149 & 54.0 & 67 & 45.9 & 216 & 51.2 & $0.19^{*}$ & $1.4(0.9,2.3)$ \\
\hline \multicolumn{9}{|c|}{ Frequency of khat chewing } \\
\hline 1-3 times/wk & 36 & 24.2 & 21 & 31.3 & 57 & 26.4 & & 1.0 \\
\hline 3-6 times/wk & 39 & 26.2 & 20 & 29.9 & 59 & 27.3 & 0.74 & $1.1(0.4,2.4)$ \\
\hline Daily & 74 & 49.6 & 26 & 38.8 & 100 & 46.3 & $0.16^{*}$ & $1.7(0.8,3.3)$ \\
\hline \multicolumn{9}{|c|}{ Cost of khat per ceremony } \\
\hline$\leq 15$ Birr & 86 & 57.7 & 44 & 65.7 & 130 & 60.2 & & 1.0 \\
\hline $16-25$ & 18 & 12.1 & 11 & 16.4 & 29 & 13.4 & 0.67 & $0.8(0.3,1.9)$ \\
\hline$>25$ & 45 & 30.2 & 12 & 17.9 & 57 & 26.4 & $0.08^{*}$ & $1.9(0.9,3.9)$ \\
\hline \multicolumn{9}{|c|}{ Alcohol consumption status } \\
\hline Never & 137 & 49.6 & 69 & 47.3 & 206 & 48.8 & & 1.0 \\
\hline Former & 30 & 10.9 & 24 & 16.4 & 54 & 12.8 & $0.12^{*}$ & $0.6(0.3,1.2)$ \\
\hline Current & 109 & 39.5 & 53 & 36.3 & 162 & 38.4 & $0.08^{*}$ & $1.1(0.7,1.6)$ \\
\hline \multicolumn{9}{|c|}{ Kind of alcohol consumed } \\
\hline Beer & 69 & 63.3 & 40 & 75.5 & 109 & 67.3 & & \\
\hline Others ${ }^{*}$ & 40 & 36.7 & 13 & 24.5 & 53 & 32.7 & $0.12^{*}$ & $1.8(0.9,3.7)$ \\
\hline \multicolumn{9}{|c|}{$\begin{array}{l}\text { Amount of coffee } \\
\text { consumed per day }\end{array}$} \\
\hline $1-2$ cups/day & 108 & 41.9 & 57 & 42.5 & 165 & 42.1 & & 1.0 \\
\hline 3-4 cups/day & 83 & 32.2 & 54 & 40.3 & 137 & 34.9 & 0.38 & $0.8(0.5,1.2)$ \\
\hline $5 \geq$ cups/ day & 67 & 26.0 & 23 & 17.2 & 90 & 23.0 & $0.14^{*}$ & $1.5(0.9,2.7)$ \\
\hline
\end{tabular}

${ }^{*} P$ value $<0.25$; others ${ }^{*}$ represent Tela, Tej, and Katicala.

poor sleeping as of the current study's result. This result agrees with the studies conducted in Yemen and northwest Ethiopia [33, 34]. Furthermore, if a person chews khat every day, the quality of sleep deteriorates more. It was indicated that daily khat chewers had above three times risk of poor sleep quality than 1-3 times per week chewers. This study agrees with the study conducted in Ethiopia among college students [35]. This could be the result of psycho-stimulant and euphorigenic effects of khat impaired with sleep center [34]. Khat consumption leads to effects that are qualitatively similar to those of amphetamine, that is, increased blood pressure, a state of euphoria, and elation with feelings of increased alertness and arousal. This may be followed by depression, irritability, anorexia, and difficulty in sleeping. Frequent use of high doses may evoke psychotic reactions [47]. The euphoric effects of khat start after about one hour of chewing. Peak plasma levels of cathinone are obtained 1.5 to 3.5 hours after the onset of chewing. Cathinone is barely detectable in blood after eight hours. First-pass metabolism of cathinone in the liver leads to the formation of norephedrine which will worsen quality of sleep.

Finally, obesity was recognized to impair sleep quality. When compared to individual with normal BMI, obese individual carries 1.2 times more risk to exhibit poor sleep quality. This result agrees with the study conducted in USA [41] but contradicts the study conducted in Regensburg, Germany [48]. The variation of the results may occur from individuals' action to manage their situation (obesity). Some manage their diets (e.g., avoiding fat food in the evening) and practice frequent exercise to reduce putative negative influences on sleep quality, while others do not.

Data of this study were obtained through home-based face-to-face interviews by qualified nurses, reliable measurements, and cautious data handling. The study provided useful information that will inform policy makers to design a strategy to reduce the prevalence of poor sleep quality that affects health of the community at large. Although the study findings identified some important factors related to sleep quality, limitations should be noted. In line with this, study design may not allow for inferring cause and effect, as a PSQI questionnaire on irregular sleep history is prone to recall bias (not the gold standard to assess sleep quality). In summary, the proportion of poor sleep quality in the study's community seems to be high and commonly affects males. Further, age of 40-49 years, low income, khat chewing, and obesity were identified as risk factors of the problem. Therefore, it 
TABLE 5: Body composition and BP measurements and their association with sleep quality among sampled adults in Jimma town, April 2016.

\begin{tabular}{|c|c|c|c|c|c|c|c|c|}
\hline \multirow{3}{*}{ Variables } & \multicolumn{6}{|c|}{ Global PSQI score } & \multirow{3}{*}{$P$ value } & \multirow{3}{*}{$\operatorname{COR}(95 \% \mathrm{CI})$} \\
\hline & \multicolumn{2}{|c|}{$\begin{array}{l}\text { Poor sleepers } \\
\quad(n=276)\end{array}$} & \multicolumn{2}{|c|}{$\begin{array}{l}\text { Good sleepers } \\
\quad(n=146)\end{array}$} & \multicolumn{2}{|c|}{ Total (422) } & & \\
\hline & $n$ & $\%$ & $n$ & $\%$ & $n$ & $\%$ & & \\
\hline \multicolumn{9}{|c|}{ Categories of BMI $\left(\mathrm{kg} / \mathrm{cm}^{2}\right)$} \\
\hline Normal & 123 & 44.6 & 60 & 41.1 & 183 & 43.4 & & 1.0 \\
\hline Underweight & 48 & 17.4 & 20 & 13.7 & 68 & 16.1 & 0.61 & $1.2(0.6,2.1)$ \\
\hline Overweight & 84 & 30.4 & 50 & 34.2 & 134 & 31.8 & 0.40 & $0.8(0.5,1.4)$ \\
\hline Obese & 21 & 7.6 & 16 & 11.0 & 37 & 8.8 & $0.02^{*}$ & $0.6(0.3,13)$ \\
\hline \multicolumn{9}{|c|}{ Male waist circumference } \\
\hline$<90 \mathrm{~cm}$ & 112 & 60.0 & 23 & 33.0 & 135 & 53.0 & & 1.0 \\
\hline$\geq 90 \mathrm{~cm}$ & 74 & 40.0 & 46 & 67.0 & 120 & 47.0 & $0.08^{*}$ & $3.0(1.3,3.7)$ \\
\hline \multicolumn{9}{|c|}{ Female waist circumference } \\
\hline$<80 \mathrm{~cm}$ & 30 & 30.0 & 26 & 40.0 & 56 & 33.5 & & 1.0 \\
\hline$\geq 80 \mathrm{~cm}$ & 72 & 70.0 & 39 & 60.0 & 111 & 66.5 & 0.25 & $0.6(0.8,3.2)$ \\
\hline \multicolumn{9}{|l|}{ SBP } \\
\hline Normal & 219 & 79.3 & 123 & 84.2 & 342 & 81.0 & & 1.0 \\
\hline Hypertension & 57 & 20.7 & 23 & 15.8 & 80 & 19.0 & $0.22^{*}$ & $1.3(0.8,2.4)$ \\
\hline \multicolumn{9}{|l|}{ DBP } \\
\hline Normal & 238 & 86.2 & 133 & 91.1 & 371 & 87.9 & & 1.0 \\
\hline Hypertensive & 38 & 13.8 & 13 & 8.9 & 51 & 12.1 & $0.12^{*}$ & $1.6(0.8,3.2)$ \\
\hline
\end{tabular}

TABLE 6: Independent factors associated with poor sleep quality (sampled $=422$ ) among adults in Jimma town, April 2016.

\begin{tabular}{|c|c|c|c|c|c|c|c|}
\hline \multirow[b]{2}{*}{ Variables } & \multirow[b]{2}{*}{$\begin{array}{c}\text { Poor sleepers }(n=276) \\
n(\%)\end{array}$} & \multirow{2}{*}{$\begin{array}{c}\text { Global PSQI score } \\
\text { Good sleepers }(n=146) \\
n(\%)\end{array}$} & \multirow[b]{2}{*}{$\begin{array}{l}\text { Total } \\
n(\%)\end{array}$} & \multicolumn{2}{|c|}{ Bivariable result } & \multicolumn{2}{|c|}{ Multivariable result } \\
\hline & & & & $P$ value & COR $(95 \% \mathrm{CI})$ & $P$ value & $\operatorname{AOR}(95 \% \mathrm{CI})$ \\
\hline \multicolumn{8}{|l|}{ Age category } \\
\hline $19-29$ years & $72(26.1)$ & $48(32.9)$ & $120(28.4)$ & & 1.0 & & 1.0 \\
\hline $30-39$ years & $73(26.4)$ & $41(28.1)$ & $114(27.0)$ & 0.53 & $1.2(0.7,2.1)$ & 0.83 & $0.9(0.5,1.7)$ \\
\hline $40-49$ years & $79(28.6)$ & $33(22.6)$ & $112(26.5)$ & 0.09 & $1.6(0.9,2.8)$ & $0.03^{* *}$ & $2.0(1.1,3.6)$ \\
\hline $50-64$ years & $52(18.8)$ & $24(16.4)$ & $76(18.0)$ & 0.03 & $1.4(0.9,2.6)$ & 0.37 & $1.4(0.7,2.8)$ \\
\hline \multicolumn{8}{|l|}{ Monthly income } \\
\hline$>1000 \mathrm{ETB}$ & $128(46.4)$ & $96(65.8)$ & $224(53.1)$ & & 1.0 & & 1.0 \\
\hline$\leq 1000 \mathrm{ETB}$ & $148(53.6)$ & $50(34.2)$ & $198(46.9)$ & 0.00 & $2.2(1.5,3.4)$ & $0.01^{* *}$ & $2.2(1.4,3.5)$ \\
\hline \multicolumn{8}{|c|}{ Khat chewing status } \\
\hline Never & $84(30.4)$ & $51(34.9)$ & $135(32.0)$ & & 1.0 & & 1.0 \\
\hline Former & $43(15.6)$ & $28(19.2)$ & $71(16.8)$ & 0.81 & $0.9(0.5,1.7)$ & 0.33 & $1.4(0.7,2.7)$ \\
\hline Current & $149(54.0)$ & $67(45.9)$ & $216(51.2)$ & 0.19 & $1.4(0.9,2.3)$ & $0.03^{* *}$ & $1.8(1.1,3.1)$ \\
\hline \multicolumn{8}{|c|}{ Frequency of khat chewing } \\
\hline $1-3$ times/wk & $36(24.2)$ & $21(31.3)$ & $57(26.4)$ & & 1.0 & & 1.0 \\
\hline 3-7 times/wk & $39(26.2)$ & $20(29.9)$ & $59(27.3)$ & 0.38 & $0.8(0.5,1.2)$ & 0.18 & $2.3(0.7,7.8)$ \\
\hline Daily & $74(49.6)$ & $26(38.8)$ & $100(46.3)$ & 0.14 & $1.5(0.9,2.7)$ & $0.04^{* *}$ & $3.4(1.2,11.1)$ \\
\hline \multicolumn{8}{|c|}{ Categories of BMI $\left(\mathrm{kg} / \mathrm{cm}^{2}\right)$} \\
\hline Normal & $123(44.6)$ & $60(41.1)$ & $183(43.4)$ & & 1.0 & & \\
\hline Underweight & $48(17.4)$ & $20(13.7)$ & $68(16.1)$ & 0.61 & $1.2(0.6,2.1)$ & 0.05 & $0.9(0.3,2.2)$ \\
\hline Overweight & $84(30.4)$ & $50(34.2)$ & $134(31.8)$ & 0.40 & $0.8(0.5,1.4)$ & 0.06 & $1.1(0.6,1.8)$ \\
\hline Obese & $21(7.6)$ & $16(11.0)$ & $37(8.8)$ & $0.02^{*}$ & $0.6(0.3,13)$ & $0.03^{* *}$ & $1.2(1.3,2.5)$ \\
\hline
\end{tabular}


is indicative that government should work towards poverty reduction, create awareness for weight reduction, and develop legislation for khat control. Finally, as sleep habits may be a marker for health status and quality of life, longitudinal study would be needed to verify cause-effect relationship of sleep quality and presumed risk factors.

\section{Conflicts of Interest}

The authors report no conflicts of interest.

\section{Acknowledgments}

The authors would like to express their appreciation to Jimma University for financial support that helped them carry out the study. They would also like to pass their heartfelt gratitude to all study participants and data collectors who were willing to participate in this study. Finally, their thanks go to their families for their laudable help.

\section{References}

[1] B. Phillips and R. Gelula, Sleep-Wake Cycle: Its Physiology and Impact on Health, National Sleep Foundation, 2006.

[2] M. Carol and P. M. Glenn, Pathophysiology: Concepts of Altered Health States, Wolters Kluwer Health Lippincott Williams \& Wilkins, New York, NY, USA, 8th edition, 2009.

[3] Sleep Councel, “The Great British bedtime report," Tech. Rep., 2013, http://www.sleepcouncil.org.uk/wp-content/uploads/2013/ 02/The-Great-British-Bedtime-Report.pdf.

[4] B. Holfeld and J. C. Ruthig, "A longitudinal examination of sleep quality and physical activity in older adults," Journal of Applied Gerontology, vol. 33, no. 7, pp. 791-807, 2014.

[5] N. F. Watson, M. S. Badr, G. Belenky et al., "Recommended amount of sleep for a healthy adult: A joint consensus statement of the American Academy of Sleep Medicine and Sleep Research Society," Journal of Clinical Sleep Medicine, vol. 11, no. 6, pp. 591592, 2015.

[6] B. Pete, "Quality sleep: the center of a healthy life, Evidence of the essential role of sleep and what happens when we don't get enough of it," 2013.

[7] J. Sutton, "For those psychologists about to rock," Psychologist, vol. 27, no. 5, pp. 320-323, 2014.

[8] T. Åkerstedt, "Sleep-gender, age, stress, work hours," in Proceedings of the WHO Technical Meeting on Sleep and Health, pp. 22-24, Bonn, Germany, 2004.

[9] C. Manmee and K. Janpol, "Sleep quality among residents and fellows in Rajavithi Hospital," Journal of the Medical Association of Thailand, vol. 100, no. 10, pp. 205-211, 2017.

[10] R. A. España and T. E. Scammell, "Sleep neurobiology from a clinical perspective," Sleep, vol. 34, no. 7, pp. 845-858, 2011.

[11] M. J. Thorpy, “Classification of sleep disorders," Neurotherapeutics, vol. 9, no. 4, pp. 687-701, 2012.

[12] A. Sadeh, "III. Sleep assessment methods," Monographs of the Society for Research in Child Development Series, vol. 80, no. 1, pp. 33-48, 2015.

[13] S. M. G. P. Togeiro and A. K. Smith, "Diagnostics methods for sleep disorders," Revista Brasileira de Psiquiatria, vol. 27, no. 1, pp. 8-15, 2005.
[14] D. J. Buysse, C. F. Reynolds III, T. H. Monk, S. R. Berman, and D. J. Kupfer, "The Pittsburgh Sleep Quality Index: a new instrument for psychiatric practice and research," Psychiatry Research, vol. 28, no. 2, pp. 193-213, 1989.

[15] G. J. Landry, J. R. Best, and T. Liu-Ambrose, "Measuring sleep quality in older adults: a comparison using subjective and objective methods," Frontiers in Aging Neuroscience, vol. 7, article 166, 2015.

[16] Understanding sleep disorders: Treatment Guide, 2016.

[17] CDC, "National sleep awareness week unhealthy sleep-related behaviors," Morbidity and Mortality Weekly Report, vol. 60, no. $8,2011$.

[18] J. F. Gaultney and J. Collins-McNeil, "Lack of sleep in the workplace: what the psychologist-manager should know about sleep," The Psychologist-Manager Journal, vol. 12, no. 2, pp. 132148, 2009.

[19] S. Stranges, W. Tigbe, F. X. Gómez-Olivé, M. Thorogood, and N.-B. Kandala, "Sleep problems: an emerging global epidemic? Findings from the INDEPTH WHO-SAGE study among more than 40,000 older adults from 8 countries across Africa and Asia," Sleep, vol. 35, no. 8, pp. 1173-1181, 2012.

[20] R. Harvey, D. Gene, and Institute of Medicine, Sleep Disorders and Sleep Deprivation: An Unmet Public Health Problem, The National Academies Press, Washington, DC, USA, 2006.

[21] Y. Mahfoud, F. Talih, D. Streem, and K. Budur, "Sleep disorders in substance abusers: How common are they?" Psychiatry, vol. 6, no. 9, pp. 38-42, 2009.

[22] J. Luo, G. Zhu, Q. Zhao et al., "Prevalence and risk factors of poor sleep quality among Chinese elderly in an urban community: results from the Shanghai aging study," PLoS ONE, vol. 8, no. 11, Article ID e81261, pp. 1-7, 2013.

[23] C. A. Crispim, R. M. Diniz, M. Dattilo, D. A. Cavagnolli, and A. P. D. Faria, "Gender differences in the relationship of sleep pattern and body composition in healthy adults," Sleep Science, vol. 4, no. 2, pp. 39-40, 2011.

[24] J. J. Madrid-Valero, J. M. Martínez-Selva, B. Ribeiro do Couto, J. F. Sánchez-Romera, and J. R. Ordoñana, "Age and gender effects on the prevalence of poor sleep quality in the adult population," Gaceta Sanitaria, vol. 31, no. 1, pp. 18-22, 2017.

[25] A. Anjum, M. A. Bajwa, and R. Saeed, "Sleep patterns; among medical and non-medical students of University of Lahore, 2010-11," Professional Medical Journal, vol. 21, no. 1, pp. 148-156, 2014.

[26] W. Lin, Q. Zhu, W. Gao et al., "Functional connectivity MR imaging reveals cortical functional connectivity in the developing brain," American Journal of Neuroradiology, vol. 29, no. 10, pp. 1883-1889, 2008.

[27] E. O. Bixler, M. N. Papaliaga, A. N. Vgontzas et al., "Women sleep objectively better than men and the sleep of young women is more resilient to external stressors: Effects of age and menopause," Journal of Sleep Research, vol. 18, no. 2, pp. 221-228, 2009.

[28] Y. Wang, J. Xie, F. Yang et al., "The prevalence of primary headache disorders and their associated factors among nursing staff in North China," The Journal of Headache and Pain, vol. 16, no. 1, article 4, 2015.

[29] P. S. Eichling and J. Sahni, "Menopause related sleep disorders," Journal of Clinical Sleep Medicine, vol. 1, no. 3, pp. 291-300, 2005.

[30] S. Lemma, S. V. Patel, Y. A. Tarekegn et al., "The epidemiology of sleep quality, sleep patterns, consumption of caffeinated beverages, and khat use among Ethiopian college students," 
Journal of Sleep Disorders: Treatment \& Care, vol. 2012, Article ID 583510, 11 pages, 2012.

[31] V. Lohsoonthorn, H. Khidir, G. Casillas et al., "Sleep quality and sleep patterns in relation to consumption of energy drinks, caffeinated beverages, and other stimulants among Thai college students," Sleep and Breathing, vol. 17, no. 3, pp. 1017-1028, 2013.

[32] K. J. Brower, "Alcohol's effects on sleep in alcoholics," Alcohol Research and Health, vol. 25, no. 2, pp. 110-125, 2001.

[33] A. Zeleke, W. Awoke, E. Gebeyehu, and F. Ambaw, "Khat chewing practice and its perceived health effects among communities of Dera Woreda, Amhara region, Ethiopia," Open Journal of Epidemiology, vol. 3, no. 4, pp. 160-168, 2013.

[34] A. D. Ali, "A pilot community-based study on association of Khat (Catha edulis) chewing practice with psychosis in Yemen," American Journal of Health Research, vol. 3, no. 2, pp. 91-96, 2015.

[35] D. Robinson, B. Gelaye, M. G. Tadesse, M. A. Williams, S. Lemma, and Y. Berhane, "Daytime sleepiness, circadian preference, caffeine consumption and Khat use among college students in Ethiopia," Journal of Sleep Disorders-Treatment \& Care, vol. 3, no. 1, 2013.

[36] M. Nakajima, A. Dokam, A. N. Kasim, M. Alsoofi, N. S. Khalil, and M. Al'Absi, "Habitual khat and concurrent khat and tobacco use are associated with subjective sleep quality," Preventing Chronic Disease, vol. 11, no. 1, Article ID 130234, pp. 1-8, 2014.

[37] N. A. Hassan, A. A. Gunaid, F. M. El-Khally, and I. M. MurrayLyon, "The effect of chewing Khat leaves on human mood," Neurosciences, vol. 7, no. 3, pp. 184-187, 2002.

[38] L. Zhang, J. Samet, B. Caffo, and N. M. Punjabi, "Cigarette smoking and nocturnal sleep architecture," American Journal of Epidemiology, vol. 164, no. 6, pp. 529-537, 2006.

[39] M. F. M. D. Araújo, R. W. A. J. F. D. Freitas, A. C. Â. S. Lima, D. C. H. R. Pereira, M. L. Ú. Zanetti, and M. M. A. C. Damasceno, "Health indicators associated with poor sleep quality among university students," Revista da Escola de Enfermagem da USP, vol. 48, no. 6, pp. 1085-1092, 2014.

[40] V. Lohsoonthorn, H. Khidir, G. Casillas et al., "The Epidemiology of Sleep Quality and Sleep Patterns among Thai College Students," 2013.

[41] R. Liu, X. Liu, L. M. Arguelles et al., "A population-based twin study on sleep duration and body composition," Obesity, vol. 20, no. 1, pp. 192-199, 2012.

[42] E. Sepahvand, R. Jalali, M. Mirzaei, and M. Kargar Jahromi, "Association between short sleep and body mass index, hypertension among acute coronary syndrome patients in coronary care unit," Global Journal of Health Science, vol. 7, no. 3, pp. 134139, 2015.

[43] R. O. Shittu, B. A. Issa, G. T. Olanrewaju et al., "Association between subjective sleep quality, hypertension, depression and body mass index in a Nigerian family practice setting," Journal of Sleep Disorders \& Therapy, vol. 3, no. 2, article 157, 2014.

[44] J. Liu, J. Hay, and B. E. Faught, "The association of sleep disorder, obesity status, and diabetes mellitus among US adults-the NHANES 2009-2010 survey results," International Journal of Endocrinology, vol. 2013, Article ID 234129, 6 pages, 2013.

[45] A. Tavasoli, M. Saeidi, and N. Hooman, "Correlation between sleep quality and blood pressure changes in Iranian children," Journal of Comprehensive Pediatrics, vol. 6, no. 1, Article ID e24805, pp. 1-6, 2015.

[46] J. Holka-Pokorska, M. Jarema, and A. Wichniak, "Androgens-a common biological marker of sleep disorders and selected sexual dysfunctions?” Psychiatria Polska, vol. 48, no. 4, pp. 701714, 2014

[47] A. A. Reda, A. Moges, S. Biadgilign, and B. Y. Wondmagegn, "Prevalence and determinants of khat (Catha edulis) chewing among high school students in Eastern Ethiopia: a crosssectional study," PLoS ONE, vol. 7, no. 3, Article ID e33946, pp. 3-7, 2012.

[48] T. Crönlein, B. Langguth, V. Busch, R. Rupprecht, and T. C. Wetter, "Severe chronic insomnia is not associated with higher body mass index," Journal of Sleep Research, vol. 24, no. 5, pp. 514-517, 2015. 


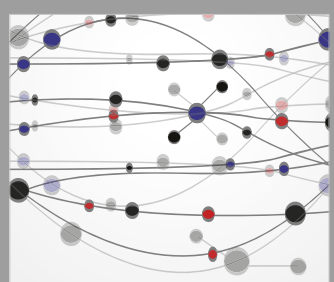

The Scientific World Journal
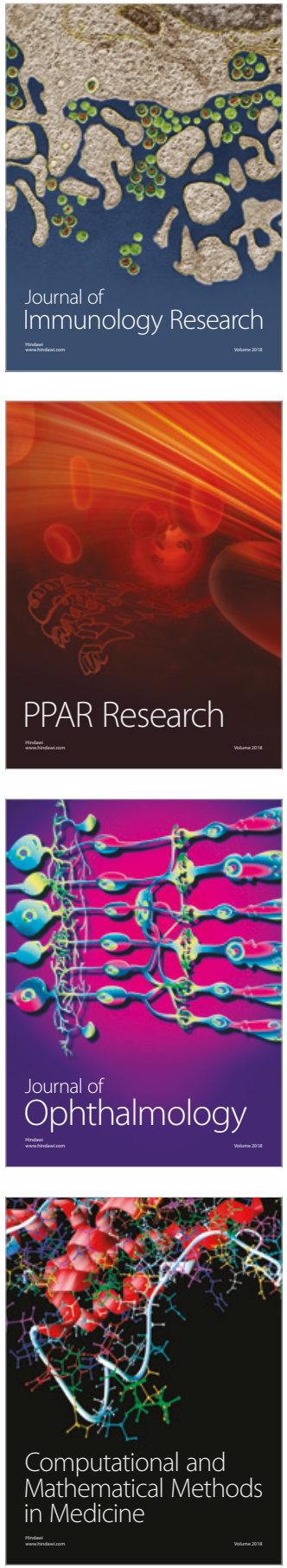

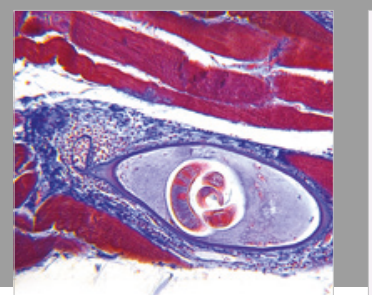

Gastroenterology Research and Practice

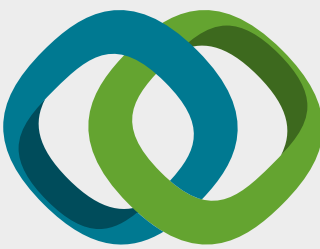

\section{Hindawi}

Submit your manuscripts at

www.hindawi.com
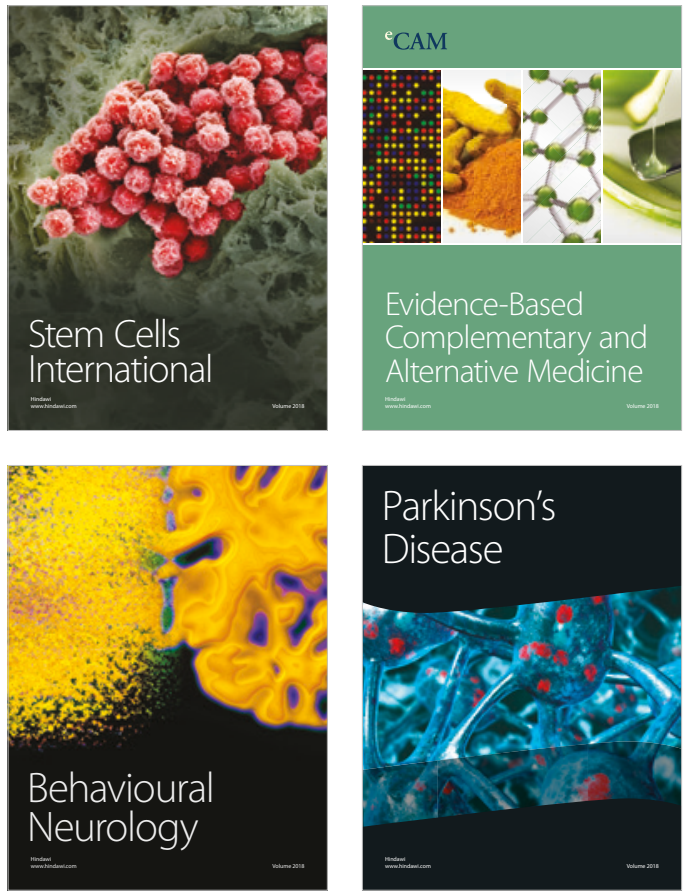

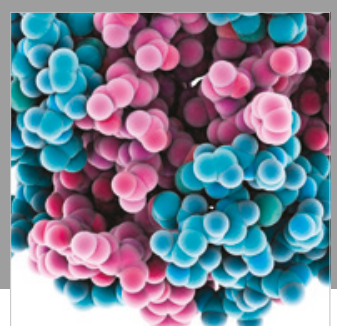

ournal of

Diabetes Research

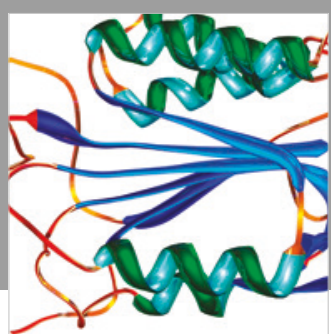

Disease Markers
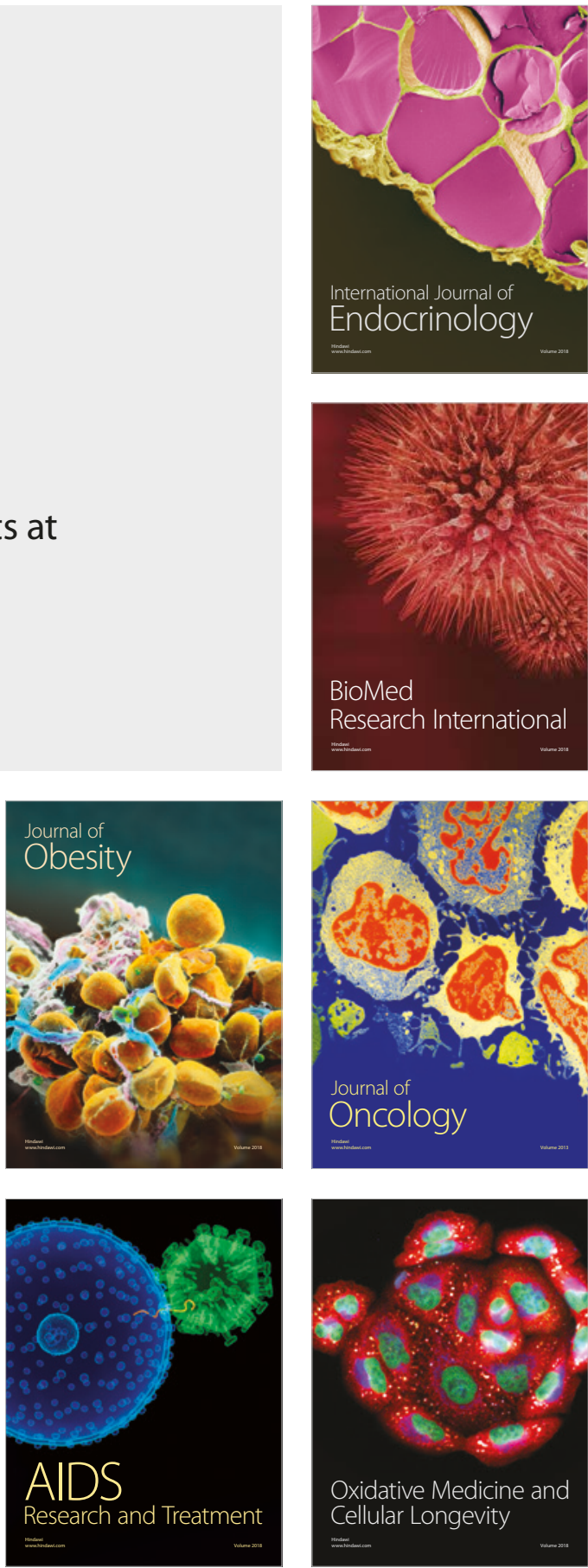